\title{
USING OF BEJAN'S HEATLINE TECHNIQUE FOR ANALYSIS OF NATURAL CONVECTION IN A DIVIDED CAVITY WITH DIFFERENTIALLY CHANGING CONDUCTIVE PARTITION
}

\author{
Ahmet Koca', Hakan F. Oztop ${ }^{2}$, Yasin $\operatorname{Varol}^{3}$, and \\ Moghtada Mobedi ${ }^{4}$ \\ ${ }^{1}$ Department of Mechatronics, Technology Faculty, Firat University, \\ Elazig, Turkey \\ ${ }^{2}$ Department of Mechanical Engineering, Technology Faculty, Firat \\ University, Elazig, Turkey \\ ${ }^{3}$ Department of Automotive Eng., Technology Faculty, Firat University, \\ Elazig, Turkey \\ ${ }^{4}$ Department of Mechanical Engineering, Izmir Institute of Technology, \\ Izmir, Turkey
}

The issue of laminar natural convection and conduction in enclosures divided by a partition with different thicknesses is investigated numerically. The partition is accepted as conductive at different thermal conductivity ratio. The cavity is filled with air, and it is heated differentially from vertical walls while horizontal walls are adiabatic. The problem is solved for different values of Rayleigh number $\left(10^{3} \leq R a \leq 10^{6}\right)$, thickness ratio of the partition, and thermal conductivity ratio $(0.1 \leq k \leq 10.0)$. It is found that both heat transfer and flow strength strongly depend on the thermal conductivity ratio of the solid material of partition and Rayleigh numbers.

\section{INTRODUCTION}

Buoyancy-induced flow and heat transfer in differentially heated enclosures is important due to wide application areas in engineering. Among these applications, double pane windows and doors, building materials, heating and cooling of buildings, heat exchanges, and solar collectors can be listed.

Conjugate natural convection in enclosures is also encountered in many engineering systems in buildings, thick walled structures, internal combustion engines, and thick walled pipes. Kaminski and Prakash [1] analyzed the conduction-natural convection problem in an enclosure. Ben Yedder and Bilgen [2] analyzed the turbulent natural convection and conduction in enclosures bounded by a massive wall. Varol et al. [3] studied the entropy generation due to conjugate natural convection heat transfer and fluid flow inside an enclosure bounded by two solid massive walls from 


\begin{tabular}{|c|c|c|c|}
\hline \multicolumn{4}{|c|}{ NOMENCLATURE } \\
\hline$a$ & thickness of top separator wall & $U, V$ & dimensionless velocities \\
\hline$b$ & thickness of bottom separator wall & $w$ & height of bottom separator wall \\
\hline$h$ & dimensional heatfunction, heat transfer & $W$ & height of enclosure, $\mathrm{m}$ \\
\hline & coefficient, $\mathrm{W} / \mathrm{m}^{2} \mathrm{k}$ & $X, Y$ & dimensionless coordinates \\
\hline$H$ & dimensionless heat function & v & kinematic viscosity, $\mathrm{m}^{2} / \mathrm{s}$ \\
\hline$g$ & gravitational acceleration, $\mathrm{m} / \mathrm{s}^{2}$ & $\theta$ & nondimensional temperature \\
\hline $\mathrm{Gr}$ & Grash of Number & $\Omega$ & nondimensional vorticity \\
\hline$\vec{i}, \vec{j}$ & cartesian unit vectors & $\beta$ & thermal expansion coefficient, $\mathrm{K}^{-1}$ \\
\hline$\vec{J}$ & total heat flux vector & $\alpha$ & thermal diffusivity, $\mathrm{m}^{2} / \mathrm{s}$ \\
\hline$k$ & thermal conductivity ratio, $k_{s} / k_{f}$ & $\Psi$ & nondimensional streamfunction \\
\hline$l$ & distance of partition in the $x$-direction & $\psi$ & dimensional streamfunction \\
\hline & $(L / 2), \mathrm{m}$ & & dimensional vorticity \\
\hline$L$ & length of enclosure, $\mathrm{m}$ & $\rho c_{p}$ & thermal capacitance \\
\hline$\overline{N u}$ & mean Nusselt number & \multicolumn{2}{|c|}{ Subscripts } \\
\hline $\mathrm{Nu}$ & local Nusselt number & A & air \\
\hline $\operatorname{Pr}$ & Prandtl number & $\mathrm{S}$ & solid \\
\hline $\mathrm{Ra}$ & Rayleigh number & $\mathrm{F}$ & fluid \\
\hline$T$ & temperature, $\mathrm{K}$ & $\mathrm{C}$ & cold \\
\hline$u, v$ & dimensional velocities, $\mathrm{m} / \mathrm{s}$ & $\mathrm{H}$ & hot \\
\hline
\end{tabular}

vertical sides at different thicknesses. The same researchers analyzed the inclination angle effects on conjugate natural convection in square-cross-sectional inclined enclosures [4]. They observed that inclination angle and other governing parameters were also used as control parameters for heat and fluid flow. Sanchez et al. [5] carried out numerical and experimental analyses for conjugate natural convection in a square cavity heated from below. They used the particle image velocimeter (PIV) technique to obtain the velocity field inside the enclosure. Similar studies related to conjugate natural convection [6-9] for different geometry can be found in the literature.

A divider can be a control parameter for natural convection heat and fluid flow in an enclosure; This is why the partitions are mostly used to control heat transfer inside the enclosure. Nuclear reactors, wall bricks, and cryogenic storage are some examples for this application. A study was performed by Turkoglu and Yucel [10] to investigate natural convection in an enclosure with conducting multiple partitions. Kahveci [11] investigated natural convection in a partitioned air-filled enclosure heated with a uniform heat flux using the differential quadrature method. He found that the average Nusselt number increases with the decrease of thermal resistance of the partition, and partition thickness has little effect on heat transfer. The similar geometry was used in his studies under different thermal boundary conditions [12, 13]. Ho and Yih [14] performed a numerical analysis on conjugate natural convection in air-filled rectangular cavities. Their results indicated that the heat transfer rate is considerably attenuated in the partitioned cavity compared to the nonpartitioned cavity. Tong and Gerner [15] made a numerical study on natural convection in partitioned rectangular cavities with a vertical partition and filled with air, and found that partitioning is an effective method of reducing heat transfer. Kangni et al. studied conjugate natural convection in enclosures having multiple partitions with finite thickness [16]. 
The heatline method can be used to illustrate the path of heat flow [17]. Kaluri et al. [18] studied natural convection with the heatline method in right-angled triangular enclosures. They investigated aspect-ratio, Pr number, and Rayleigh number effects on heat and fluid flow inside the enclosure. Dalal and Das [19] used the heatline method for a two-dimensional cavity with a wavy right vertical wall. They studied a wide range of Rayleigh numbers $\left(10^{0}-10^{6}\right)$. Laminar natural convection in a square cavity with distributed heat sources was studied by Kaluri et al. [20]. They found that heatlines a suitable guidelines to assemble discrete heat sources. Natural convection in trapezoidal enclosures with the heatline method was studied by Basak et al. [21]. Uniformly and nonuniformly heated bottom wall effects on heat and fluid flow were investigated by the researchers. They found that the average heat transfer rate does not vary significantly for nonuniform heating of bottom wall. The same geometry with different boundary conditions was also studied [22]. Mobedi and Oztop [23] studied conjugate heat transfer in an enclosure with a thick solid ceiling using the heatline method. They investigated thermal conductivity ratio effects on heat and fluid flow. Conjugate heat transfer in a square enclosure using the heatline concept was studied by Deng and Tang [24]. Natural convection in a triangular enclosure filled with porous media was investigated by Varol et al. [25]. They used dimensionless heatfunction to visualize the heat transport due to buoyancy forces. The researchers investigated the same problem with a different application [26].

The main aim of this work is to present the effects of a differentially thickness changed conductive partition on natural convection heat transfer in an enclosure by using Bejans' heatline technique. The cavity is filled with air and it is enclosed in a square cavity with a hot left wall, cold right wall, and adiabatic horizontal walls. A detailed literature survey showed that most of the studies on a natural convection partitioned cavity have been performed by assuming a fixed partition thickness. Thus, the present study involves application of a partition with variable thickness and contributes new information to the literature.

\section{DEFINITION OF THE PHYSICAL MODEL}

The solid model of the considered geometry is shown in Figure 1a. The red and blue walls indicate the hot and cold walls of the enclosure, respectively. The enclosure is too long and the problem can be reduced into 2-D natural convection heat transfer by neglecting the end effects. The 2-D square enclosure with height of $W$ and width of $L(W=L)$ is shown in Figure $1 b$. Both side of the partition are filled with air. The cavity is heated from the left vertical wall and cooled from the right, while the top and bottom walls are adiabatic. The cavity is divided by a wall with different thickness and thermal conductivity $\left(k_{S}\right)$. The thickness of the half bottom side of the partition is greater than the upper half. In other words, the thickness of the bottom wall is different than the upper wall. The ratio $b / a$, indicates the thickness ratio of the partition where $a$ and $b$ are the thickness of top and bottom separator walls. The partition is located at the middle of the enclosure $(w)$, and it is not changed throughout the present study. It should be noted that there is no mixing between right and left regions of the cavity, and the middle impermeable wall completely separates the left and right regions. However, heat can be exchanged between the right and left regions via the middle wall. 


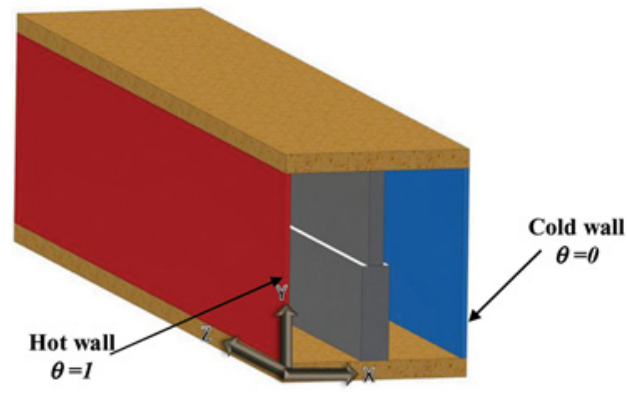

(a)

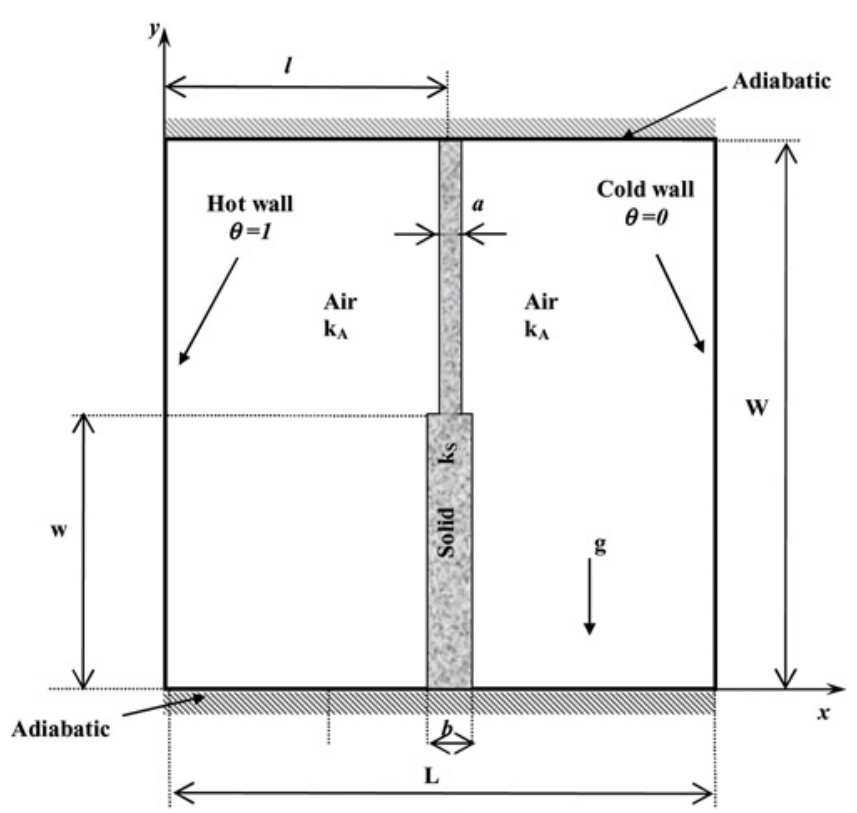

(b)

Figure 1. Views of the studied cavity. a) solid model and b) 2-D model (color figure available online).

\section{GOVERNING EQUATIONS AND BOUNDARY CONDITIONS}

The studied flow is laminar, incompressible, and steady-state and fluid properties are assumed to be constant except density. The effect of buoyancy is included via the well-known Boussinesq's approximation. As previously mentioned, the depth of the enclosure is assumed to be long enough so that the airflows may be conceived with 2-D motion. It is assumed that the walls of the enclosures and partition are solid and impermeable. The viscous dissipation and radiation effects are neglected. The gravity acts in a vertical direction. The vorticity-streamfunction approach is used to determine velocity field in the cavity. For a two-dimensional flow under the above assumption, the dimensionless form of vorticity and streamfunction can 
be written as follows.

$$
\begin{aligned}
\frac{\partial^{2} \Omega}{\partial X^{2}}+\frac{\partial^{2} \Omega}{\partial Y^{2}}= & \frac{1}{\operatorname{Pr}}\left(\frac{\partial \Psi}{\partial Y} \frac{\partial \Omega}{\partial X}-\frac{\partial \Psi}{\partial X} \frac{\partial \Omega}{\partial Y}\right)-\operatorname{Ra} \frac{\partial \theta}{\partial X} \\
& \frac{\partial^{2} \Psi}{\partial X^{2}}+\frac{\partial^{2} \Psi}{\partial Y^{2}}=-\Omega
\end{aligned}
$$

where $\Psi$ and $\Omega$ are dimensionless streamfunction and vorticity. They are defined as follows.

$$
\Psi=\frac{\psi P r}{v}, \Omega=\frac{\omega(L)^{2} P r}{v}
$$

$\psi$ and ware dimensional streamfunction and vorticity.

$$
\begin{gathered}
u=\frac{\partial \psi}{\partial y}, v=-\frac{\partial \psi}{\partial x} \\
\omega=\left(\frac{\partial v}{\partial x}-\frac{\partial u}{\partial y}\right)
\end{gathered}
$$

The energy equation for fluid that moves in the cavity can be written as follows.

$$
\frac{\partial^{2} \theta}{\partial X^{2}}+\frac{\partial^{2} \theta}{\partial Y^{2}}=\frac{\partial \Psi}{\partial Y} \frac{\partial \theta}{\partial X}-\frac{\partial \Psi}{\partial X} \frac{\partial \theta}{\partial Y}
$$

For the partition which separates the cavity into two equal parts, the energy equation can be written as follows.

$$
\frac{\partial^{2} \theta}{\partial X^{2}}+\frac{\partial^{2} \theta}{\partial Y^{2}}=0
$$

The following parameters are used to make the above heat and fluid flow equations nondimensionalized.

$$
\begin{gathered}
X=\frac{x}{L}, Y=\frac{y}{L}, \Psi=\frac{\psi P r}{v}, \Omega=\frac{\omega(L)^{2} P r}{v}, \theta=\frac{T-T_{C}}{T_{H}-T_{C}} \\
\operatorname{Pr}=\frac{v}{\alpha}, \mathrm{Gr}=\frac{g \beta L^{3}\left(T_{H}-T_{C}\right)}{v^{2}} \mathrm{Ra}=\mathrm{Gr} \cdot \operatorname{Pr}
\end{gathered}
$$

Equations (1), (2), (6), and (7) are elliptic type partial differential equations, and they require boundary conditions in order to be solved. Considering Figure $1 b$, the boundary conditions for these equations can be written as follows.

$$
\text { On the hot wall : } \quad \Psi=0, \Omega=-\frac{\partial^{2} \Psi}{\partial X^{2}}, \theta=1
$$




$$
\begin{array}{cl}
\text { On the cold wall : } & \Psi=0, \Omega=-\frac{\partial^{2} \Psi}{\partial X^{2}}, \theta=0 \\
\text { On adiabatic walls : } & \Psi=0, \Omega=-\frac{\partial^{2} \Psi}{\partial Y^{2}}, \frac{\partial \theta}{\partial Y}=0
\end{array}
$$

On the right interface and left sides of the partition, (i.e., $X=\frac{L}{2} \pm \frac{\varepsilon}{2}$ ) :

$$
\left.k \frac{\partial \theta}{\partial X}\right|_{S}=\left.\frac{\partial \theta}{\partial X}\right|_{F}
$$

where $\varepsilon$ is $b$ for lower and $a$ for upper part of partition. The symbol of $k$ is the thermal conductivity ratio $\left(k_{s} / k_{f}\right)$.

\section{HEATFUNCTION}

For a two-dimensional steady and incompressible heat and fluid flow without heat generation, the components of the heat flux vector, containing the diffusion and convection transport in $x$ and $y$ directions, can be written as follows.

$$
\begin{gathered}
J_{x}=\left(\rho c_{p}\right) u\left(T-T_{c}\right)-k \frac{\partial T}{\partial x} \\
J_{y}=\left(\rho c_{p}\right) v\left(T-T_{c}\right)-k \frac{\partial T}{\partial y}
\end{gathered}
$$

where $T_{c}$ is the reference temperature, and $\rho c_{p}$ and $k$ are thermal capacitance and thermal conductivity ratio of fluid. The total heat flux vector, $\vec{J}$, is the vectorial sum of the two heat flux components:

$$
\vec{J}=J_{x} \vec{i}+J_{y} \vec{j}
$$

The vectors $\vec{i}$ and $\vec{j}$ represent Cartesian unit vectors. Application of energy conservation law on a finite volume in the flow field and considering the heat flux definition (Eqs. (13) and (14)) yields the energy equation for the fluid flow.

$$
\frac{\partial J_{x}}{\partial x}+\frac{\partial J_{y}}{\partial y}=\left(\rho c_{p}\right)\left(\frac{\partial u T}{\partial x}+\frac{\partial v T}{\partial y}\right)-k\left(\frac{\partial 2 T}{\partial x^{2}}+\frac{\partial^{2} T}{\partial y^{2}}\right)=0
$$

By defining $h$ as a continuous scalar function, the dimensional heatfunction can be written in a differential form [23].

$$
-\frac{\partial h}{\partial x}=J_{y} ; \frac{\partial h}{\partial y}=J_{x}
$$

By substituting Eq. (17) into Eqs. (13) and (14), taking derivatives with respect to $y$ and $x$, and subtracting the resulting equations from each other, a partial differential equation for the heatfunction can be obtained.

$$
\frac{\partial^{2} h}{\partial x^{2}}+\frac{\partial^{2} h}{\partial y}=\left(\rho c_{p}\right)\left(\frac{\partial u T}{\partial y}-\frac{\partial v T}{\partial x}\right)
$$


The convection term which appears on the right side of Eq. (18) acts as a source term. It should be mentioned that the defined heatfunction $h$ includes both the diffusion and convection modes of heat transfer. The solution of Eq. (18) yields the values of the dimensional heatfunction for the all nodes of a computational domain, and contour plots of the heatfunction values provide dimensional heatline patterns. By employing the dimensionless parameters presented by Eq. (11), the dimensionless heatfunction can be written as follows.

$$
\begin{gathered}
-\frac{\partial H}{\partial X}=V \theta-\frac{\partial \theta}{\partial Y} \\
\frac{\partial H}{\partial Y}=U \theta-\frac{\partial \theta}{\partial X}
\end{gathered}
$$

where $H$ is the dimensionless heatfunction as follows.

$$
H=\frac{h}{\left(T_{h}-T_{c}\right) k_{f}}
$$

By performing the mathematical manipulations similar to the procedure for obtaining Eq. (18) from Eqs. (13) and (14), the following dimensionless heatfunction equation can be obtained from Eqs. (19) and (20).

$$
\frac{\partial^{2} H}{\partial X^{2}}+\frac{\partial^{2} H}{\partial Y^{2}}=\left(\frac{\partial U \theta}{\partial Y}-\frac{\partial V \theta}{\partial X}\right)
$$

For the solid region, since there is no velocity field and conduction heat transfer is the only mechanism of heat transfer, the heatfunction equation becomes as follows.

$$
\frac{\partial^{2} H}{\partial X^{2}}+\frac{\partial^{2} H}{\partial Y^{2}}=0
$$

The boundary conditions for the dimensionless heatfunction equation (Eqs. (22) and (23)) are obtained from the integration of Eqs. (19) and (20) along the considered boundary. For instance, the following equation can be used to determine the values of heatfunction at the left wall of the cavity [23].

$$
\text { For } X=0 ; 0<Y \leq 1 \quad H(0, Y)=H(0,0)-\left.\int_{0}^{Y} \frac{\partial \theta}{\partial X}\right|_{X=0} d Y
$$

The same rule can be used for the interface between the solid partition and fluid. For example, the values of heatfunction for the left lower part of the wall can be obtained from the following relation.

$$
\text { For } X_{l}=\frac{1}{2}-\frac{1}{2} \frac{L}{b} ; 0<Y \leq \frac{1}{2} \quad H\left(X_{l}, Y\right)=H\left(X_{l}, 0\right)-\left.\int_{0}^{Y} \frac{\partial \theta}{\partial X}\right|_{X=l} d Y
$$


The value of heatfunction at the upper and lower adiabatic walls is not changed since no heat flux exists at the upper and bottom walls. The value of heat flux at the origin is assumed as zero, $H(0,0)=0$.

\section{HEAT TRANSFER RELATIONS}

\subsection{Mean Nusselt Number}

The average heat transfer coefficient $h$ can be represented in dimensionless form by defining a proper Nusselt number. The local Nusselt number is found for the hot and cold sides of the partition which separates the enclosure.

$$
\begin{aligned}
& \mathrm{Nu}=\left.\frac{\partial \theta}{\partial X}\right|_{X=(L / 2)-(\varepsilon / 2)} \quad \text { (hotside) } \\
& \mathrm{Nu}=\left.\frac{\partial \theta}{\partial X}\right|_{X=(L / 2)+(\varepsilon / 2)} \quad(\text { coldside })
\end{aligned}
$$

The mean Nusselt number of each side can be determined from the following equation.

$$
\overline{\mathrm{Nu}}=\int_{0}^{1} \mathrm{Nu} \cdot d y
$$

\subsection{Numerical Method}

The numerical method used in the present study is based on the finite difference method. The governing equations (Eqs. (1)-(9)) are discretized, and the set of algebraic equations are solved using the successive under relaxation (SUR) technique. A regular grid was used for the whole computational domain. The central difference method is applied for discretization of equations. The convergence criterion

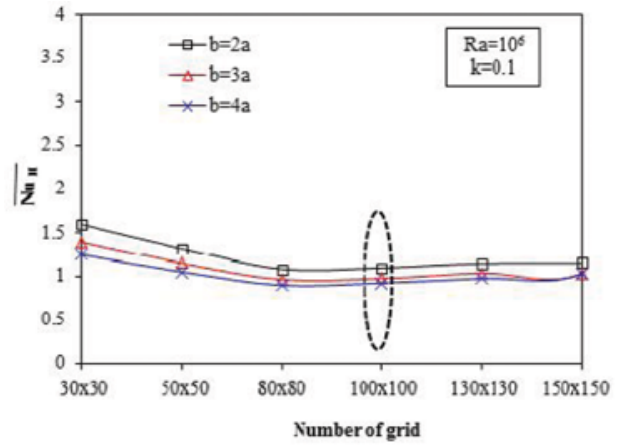

(a)

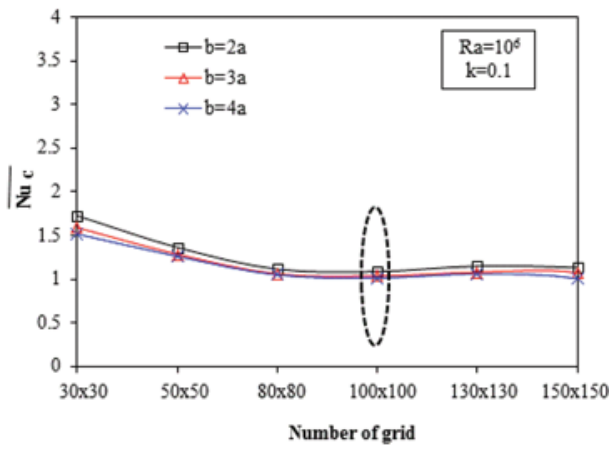

(b)

Figure 2. Grid test at $\mathrm{Ra}=10^{6}$ for $k=0.1: a$ ) hot side and $b$ ) cold side (color figure available online). 
Table 1. Comparison of the values of mean Nusselt number for the square cavity with a differentially heated cavity for conjugate hat transfer from Sanchez et al. [5] and Kaminski and Prakash [1]

\begin{tabular}{lrccc}
\hline Gr & \multicolumn{1}{c}{$k$} & $\begin{array}{c}\overline{\mathrm{Nu}}(\text { Sanchez } \\
\text { et al. [5]) }\end{array}$ & $\begin{array}{c}\overline{\mathrm{Nu}} \text { (Kaminski } \\
\text { and Prakash [1]) }\end{array}$ & $\overline{\mathrm{Nu} \text { (present) }}$ \\
\hline $10^{5}$ & 5 & 2.078 & 2.08 & 2.187 \\
$10^{5}$ & 25 & 3.49 & 3.42 & 3.394 \\
$10^{6}$ & 5 & 2.80 & 2.87 & 2.741 \\
$10^{6}$ & 25 & 5.91 & 5.89 & 5.815 \\
\hline
\end{tabular}

is chosen as $10^{-4}$ for all depended variables and 0.1 is taken for the under-relaxation parameter. In the study, a regular grid is used and the grid dimension was taken as $101 \times 101$. Figures $2 a$ and $2 b$ show the variation of average Nusselt number of the hot and cold sides of the partition with the number of the grids for an enclosure with $k=0.1$ when $\mathrm{Ra}=10^{6}$. As seen, the $101 \times 101$ number of grid is sufficient to obtain accurate results for the problem.

\subsection{Validation of Numerical Code}

Validation of the present code was performed by considering two different studies from the available literature by Kaminski and Prakash [1] and Sanchez et al. [5]. In their work, the cavity is filled with a single viscous fluid and bounded by single or double walls with finite length and different thermal conductivity. A comparison between these studies and our code is performed, and the results are listed in Table 1. As seen from the table, the obtained results show good agreement with the results reported in the literature.

\section{RESULTS AND DISCUSSION}

Numerical results for natural convection heat transfer for a divided square cavity by partition having different thicknesses are described here. As mentioned above, the governing parameters are Rayleigh numbers, thickness ratio of the partition, and thermal conductivity ratio between solid and the fluid. The results are shown with streamlines, isotherms, heatlines, and velocity profiles. The heatline method can be used to illustrate the path of convection heat flow, and streamlines give an idea of flow pattern. The air is chosen as a working fluid having $\operatorname{Pr}=0.7$.

Streamlines (on the left), isotherms (on the middle), and heatlines (on the right) at different Rayleigh numbers for $b=3 a$ when $k=1.0$ are presented in Figures $3 a-3 d$. Figure $3 a$ shows streamline, isotherm, and heatline patterns for $\mathrm{Ra}=10^{3}$. The convection effect is small due to a small value of Rayleigh number, and egg-shaped cells were formed in the left and right chests with $\psi_{\text {min }}=-0.19$ and $\psi_{\text {min }}=-0.14$, respectively. These two cells rotate in a clockwise direction. The partition behaves as a forward facing step (based on flow rotation direction), and the flow follows the step on the left side due to high velocity. At the right chest, the strength of the flow becomes smaller due to low interaction between the hot and cold walls. For the whole cavity, the 

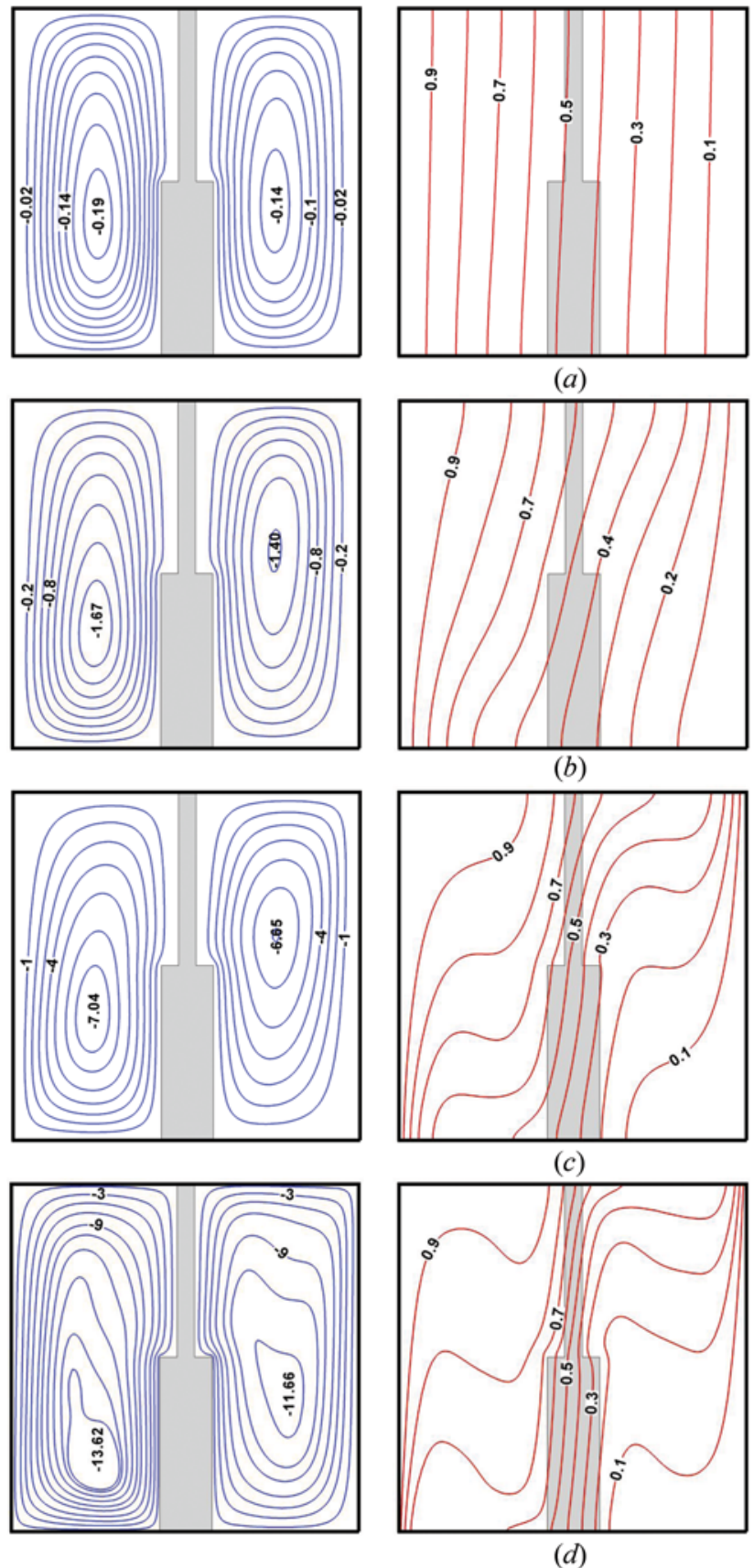

(a)

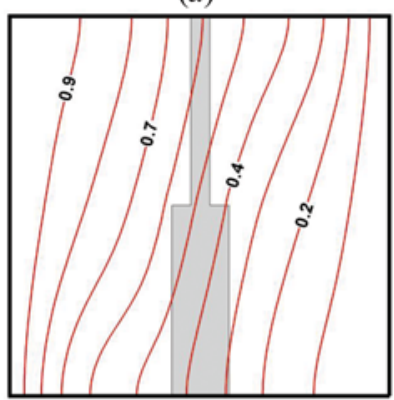

(b)

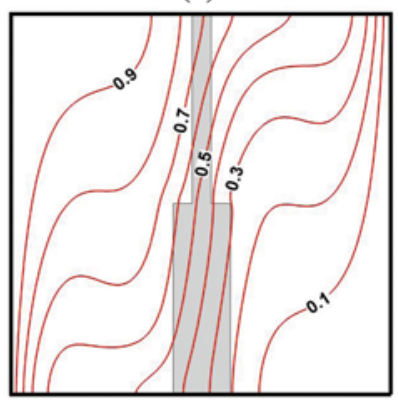

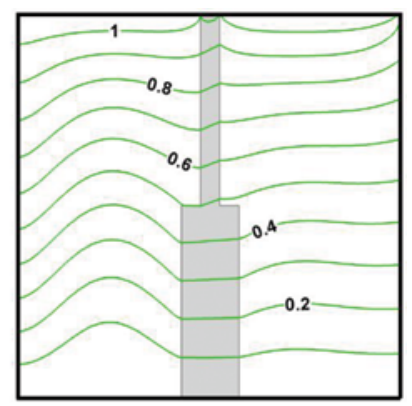
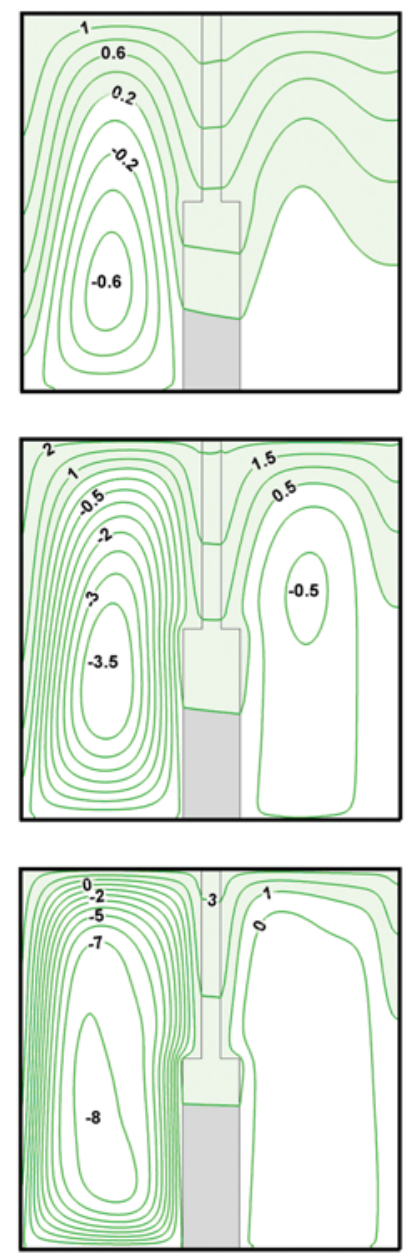

Figure 3. Streamlines (left), isotherms (middle), and heatlines (right) at different Rayleigh numbers for $b=3 a, k=1.0 a$ ) $\left.\left.\mathrm{Ra}=10^{3}, b\right) \mathrm{Ra}=10^{4}, c\right) \mathrm{Ra}=10^{5}$, and $d$ ) $\mathrm{Ra}=10^{6}$ (color figure available online). 
isotherms are almost parallel to the differentially heated wall, since $k=1$ and conduction mode of heat transfer becomes dominant. For the same reason, heatline patterns are parallel to the horizontal walls, showing almost one-dimensional heat transfer from hot to the cold plate. At $\mathrm{Ra}=10^{4}$, the isotherms become almost diagonal and they are distorted from the vertical pattern by increasing the Rayleigh number. The increase of convective effect, increasing the strength of the flow, and the magnitude of streamfunction values are increased in the right and left regions. The increase of Rayleigh number from $10^{3}$ to $10^{4}$ also changes heatline patterns due to increasing flow velocity. The path of the heat from the hot to the cold wall is colored by light green. Heat is transferred from the hot wall to air and the warm air flows up due to a buoyancy effect. Then, it flows horizontally in the top region of the left part of the cavity. Heat flows downward since the left surface of the partition is colder than circulated air. Heat of circulated air is transferred to the middle wall and passes through the middle wall. The air of the right part of the cavity receives heat and it flows up due to a buoyancy effect. Similarly, air flows parallel in the top region of the left part and then it moves down and releases heat to the cold wall. As seen from heatline distribution, two regions exist in the cavity. In the first region, shown in gray, heat is transferred from the left to the right wall. It is the active region and the continuous heatline from the left to right wall can be seen. The second region, which is in white, is the passive region. In this region, heat rotates and a heat vortex occurs. Although the heatlines in this region is continuous, they do not cross the left and right walls. The whole of the middle wall is in active regions. The increase of Rayleigh number from $\mathrm{Ra}=10^{4}$ to $\mathrm{Ra}=10^{5}$ increases the velocity gradient in the cavity and, therefore, the magnitude of streamfunction increases. Isotherms in the center of the left and right parts of the cavity become parallel to the horizontal wall. Heatline is squeezed in the top regions of the right and left parts. Most of left and right parts are not colored indicating heat circulation in these regions. It should be mentioned that the difference between the maximum values of heatfunction increases with an increase of Rayleigh number, showing the increase of heat transfer from the hot to cold wall. By increasing Rayleigh number from $\mathrm{Ra}=10^{4}-10^{5}$, the increase of the difference between the maximum and minimum heatfunction values can be observed. For high values of Rayleigh number, heatlines patterns are more squeezed in the top regions and heat transfer from the left to the right wall increases. As seen, the passive area in which heat in circulated are also expanded.

Figure 4 shows streamlines (on the left), isotherms (on the middle) and heatlines (on the right) at different thicknesses of partition for $k=10$ and $\mathrm{Ra}=10^{5}$. In this case, the thin part is taken as fixed but the thickness of the bottom part is changed. When the figures are compared, it is observed that the increase of the bottom side of the middle wall does not have an important influence on streamline, isotherm, and heatline patterns. As seen from the figure, two circulation cells are formed in each chest of the enclosure. Both of them rotate in a clockwise direction. The thickness of the partition affects the flow strength. Lower flow strength is formed with higher partition thickness. In all cases, values of streamfunction become the same at each chest. As an expected result, the conduction mode of heat transfer becomes effective at the lower part of the enclosure. Partition thickness is not an effective parameter on heatlines. Heatline patterns in the wall also prove a two-dimensional heat transfer in the wall, since it is not horizontal. If the heatline patterns and isotherms in the middle wall 

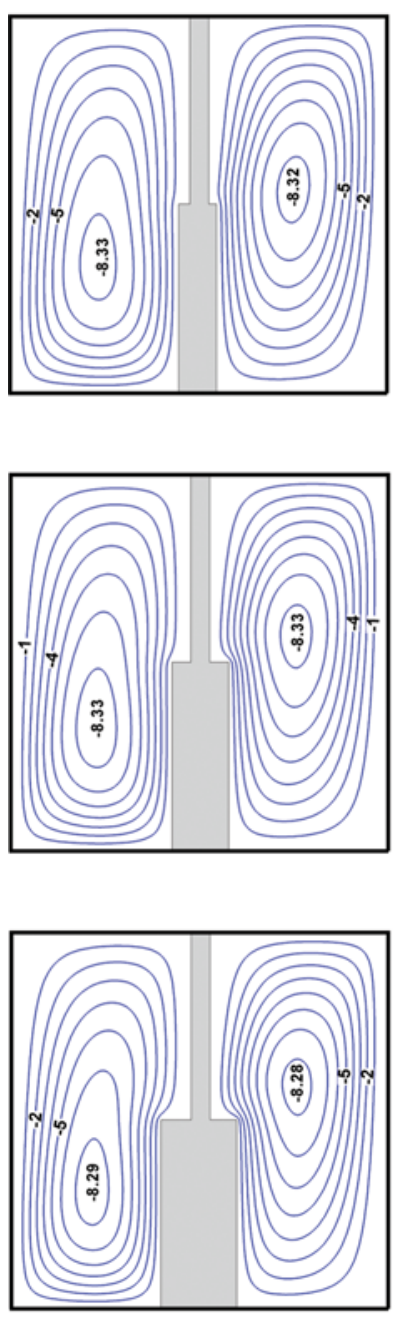

(c)
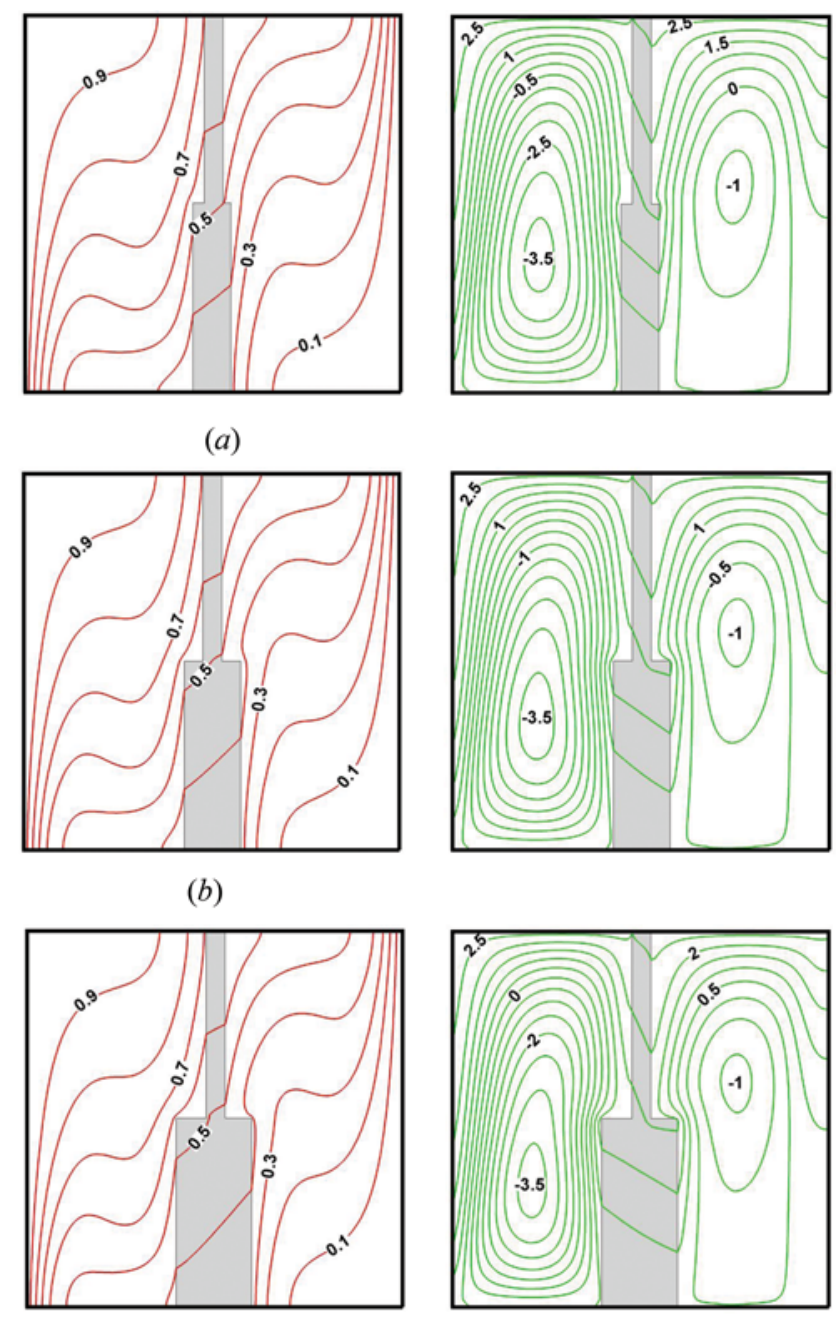

(a)
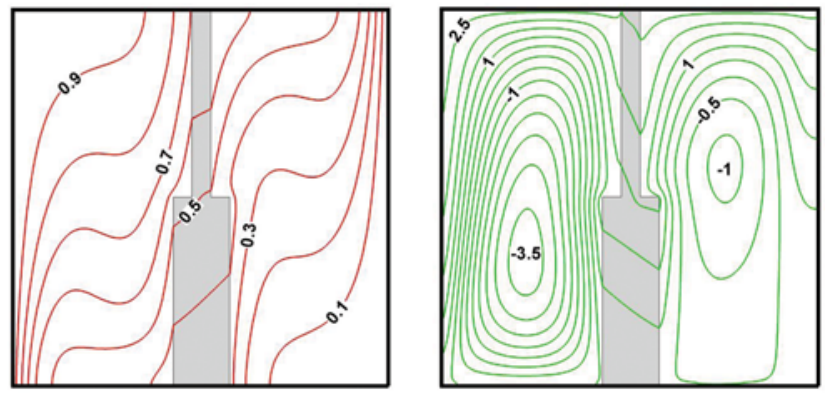

(b)

Figure 4. Streamlines (left), isotherms (middle), and heatlines (right) at different thicknesses of partition for $\left.\left.k=10, \operatorname{Ra}=10^{5} a\right) b=2 a, b\right) b=3 a$, and c) $b=4 a$ (color figure available online).

are observed carefully, it can be seen that heatline patterns are perpendicular to the isotherms since no convection effect exists in the wall.

Figure 5 is presented to observe the effect of the thermal conductivity ratio on the heat and fluid flow in the cavity. It shows the streamlines, isotherms, and heatlines inside a cavity for different thermal conductivity ratio $(k)$ when $b=2 a$ and $\mathrm{Ra}=10^{6}$. The flow strength becomes stronger in the left side than that of the right side. In this case, the partition becomes an adiabatic wall and heat transportation from the left to right wall becomes very weak. Thus, values of heatlines become very low at the right chest for $k=0.1$. The extreme value of heatlines decreases in the left side with increasing thermal conductivity due to energy transformation from left to 

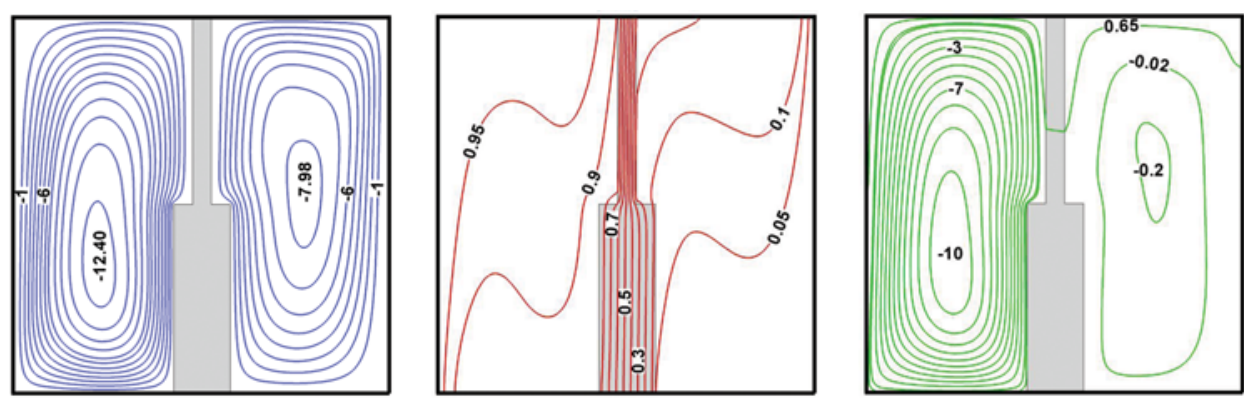

(a)
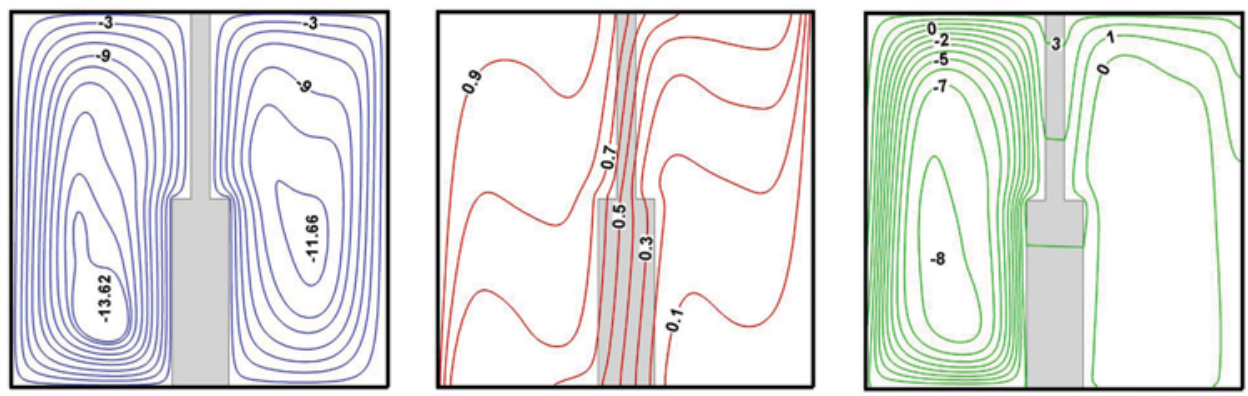

(b)
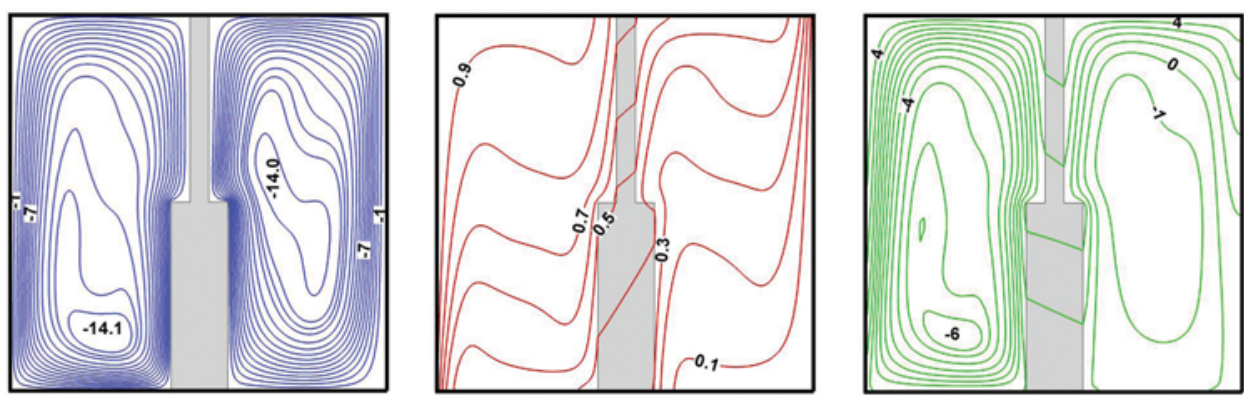

(c)

Figure 5. Streamlines (left), isotherms (middle), and heatlines (right) for different thermal conductivity ratios $(k)$ for $b=2 a, \mathrm{Ra}=10^{6}$. a) $\left.k=0.1, b\right) k=1.0$, and $k=10.0$ (color figure available online).

right. Isotherms are distributed as parallel to vertical walls inside the partition. In this case, heatlines inside the partition are parallel to horizontal walls. This indicates the full conduction heat transfer inside the partition (Figure $5 a$. Thus, the effects of the step are identical in both sides of the chests. Flow strength becomes very high with increasing the thermal of thermal conductivity. Each chest behaves as a separate cavity for $k=10.0$.

Variation of velocity profiles is presented for $\mathrm{Ra}=10^{3}$ (on the left) and $\mathrm{Ra}=10^{5}$ (on the right) at the mid-section in a vertical way for different thicknesses of the partition for different values of thermal conductivities in Figure 6. Velocity profiles exhibit almost the same behavior for all values of thickness of the partition 

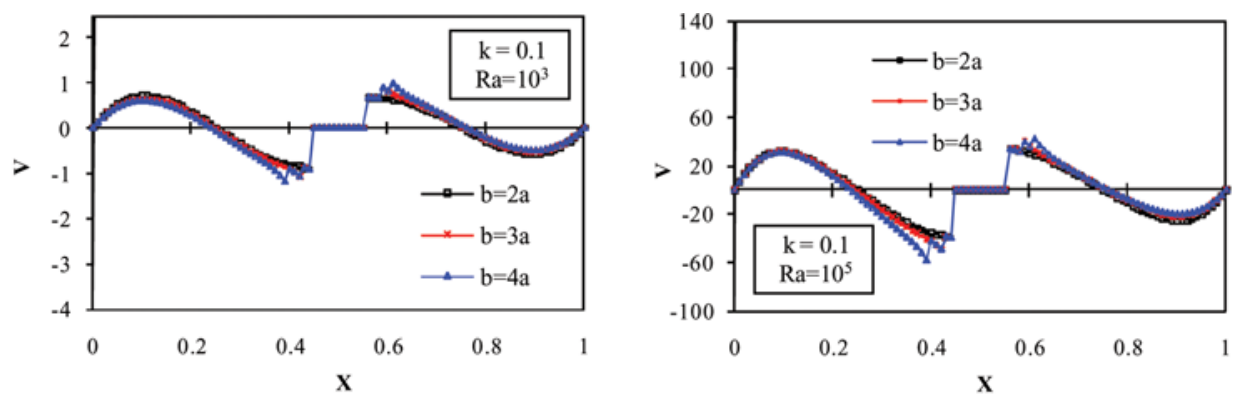

(a)
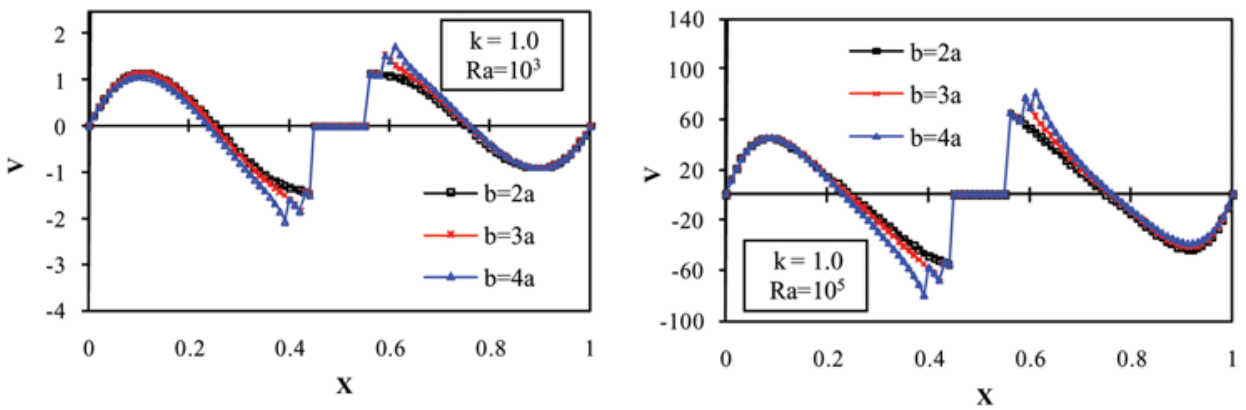

(b)
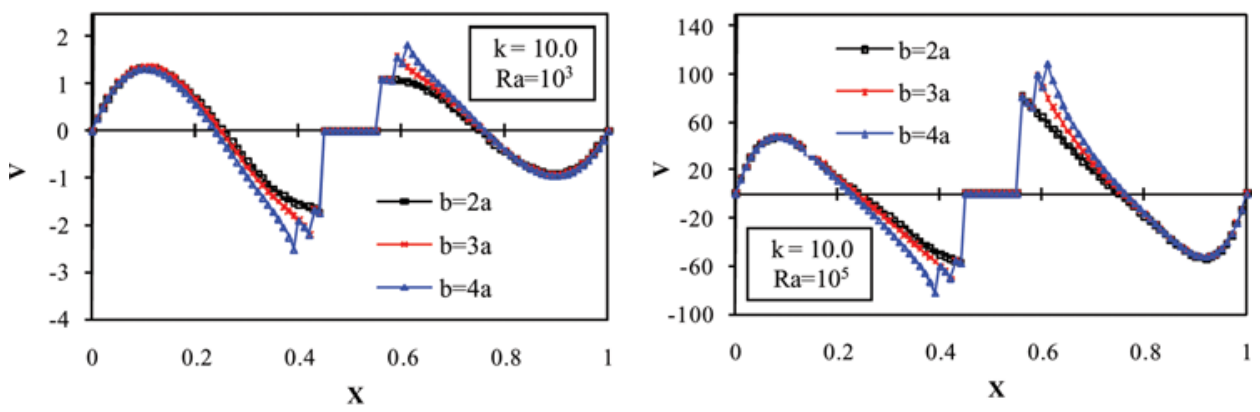

(c)

Figure 6. Comparison of velocity profiles for $\mathrm{Ra}=10^{3}$ (on the left) and $\mathrm{Ra}=10^{5}$ (on the right) at the mid-section in a vertical way for different thicknesses of the partition. $a$ ) $k=0.1, b$ ) $k=1.0$, and c) $k=10.0$ (color figure available online).

at $k=0.1$ and 1.0. However, the lower values (in the left chest) and higher values (in the right chest) are obtained for $k=10.0$. Higher values are obtained for $\mathrm{Ra}=10^{5}$. However, trends for velocity profiles are almost the same in the case of $\mathrm{Ra}=10^{3}$. Nevertheless, the maximum velocity was observed in $\mathrm{Ra}=10^{5}, k=10$, and $b=4 a$ (Figure $6 c$ ). Variation of Rayleigh number becomes insignificant on locations of maximum and minimum values of velocity profiles.

Variations of the local Nusselt number on the hot and cold sides of the middle wall for different thicknessess of the partition are presented in Figures 7 and 8, 

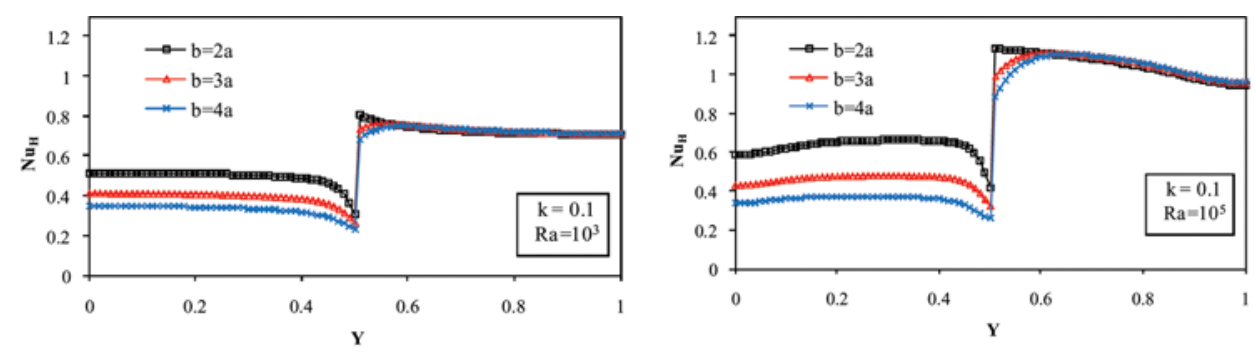

(a)
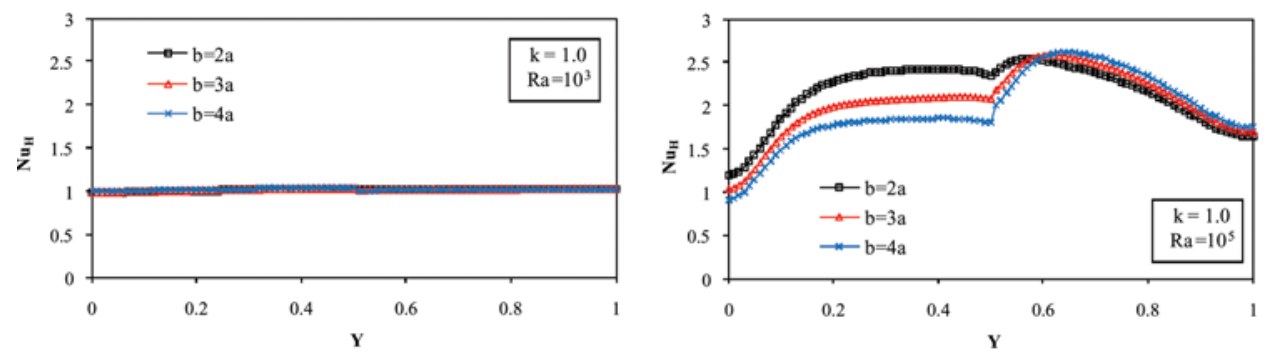

(b)
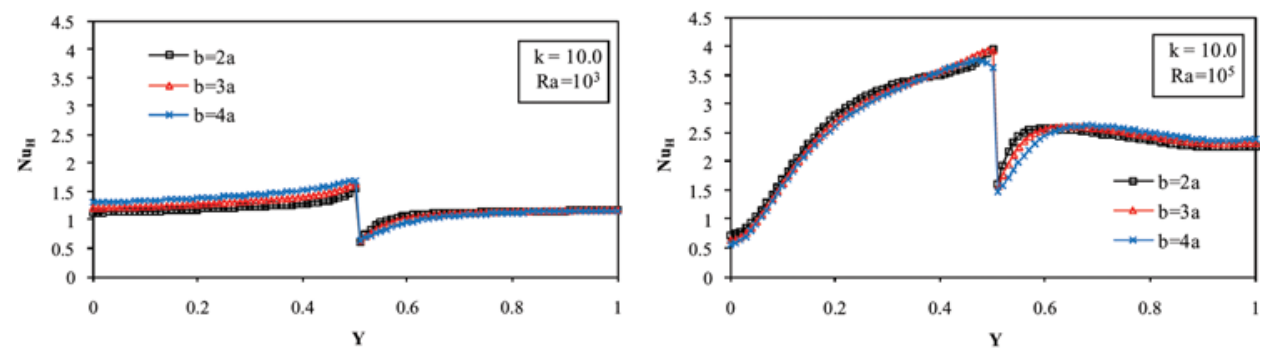

(c)

Figure 7. Variation of the hot side local Nusselt number for $\mathrm{Ra}=10^{3}$ (on the left) and $\mathrm{Ra}=10^{5}$ (on the right) along the hot wall for different thicknesses of the partition. $a$ ) $k=0.1, b) \mathrm{k}=1.0$, and $c$ ) $\mathrm{k}=10.0$ (color figure available online).

respectively. These figures are presented to show effects of partition thickness, Rayleigh number ( $\mathrm{Ra}=10^{3}$ (on the left) and $\mathrm{Ra}=10^{5}$ (on the right), and dimensionless thermal conductivity values at the mid-section in a vertical way. As seen from the figures, the variation of the local Nusselt number exhibits different trends for left and right chests. Variation of thickness of the partition becomes insignificant in the right chest for $k=0.1$ for $\mathrm{Ra}=10^{3}$ and $k=1.0$ at $\mathrm{Ra}=10^{5}$. Conduction mode of heat transfer becomes dominant for $\mathrm{Ra}=10^{3}$ and $k=1.0$ for Figure $6 b$. For $\mathrm{Ra}=10^{3}$, the local Nusselt number in $Y$ direction does not highly change since the conduction mode of heat transfer is dominant in the region. For the $\mathrm{Ra}=10^{5}, k=10$ case, a minimum local Nusselt number occurs at the bottom of the partition and a maximum forms at the top of the wider partition where $Y=0.5$. As an expected result, higher heat transfer is formed in both chests for higher values of Rayleigh number and 

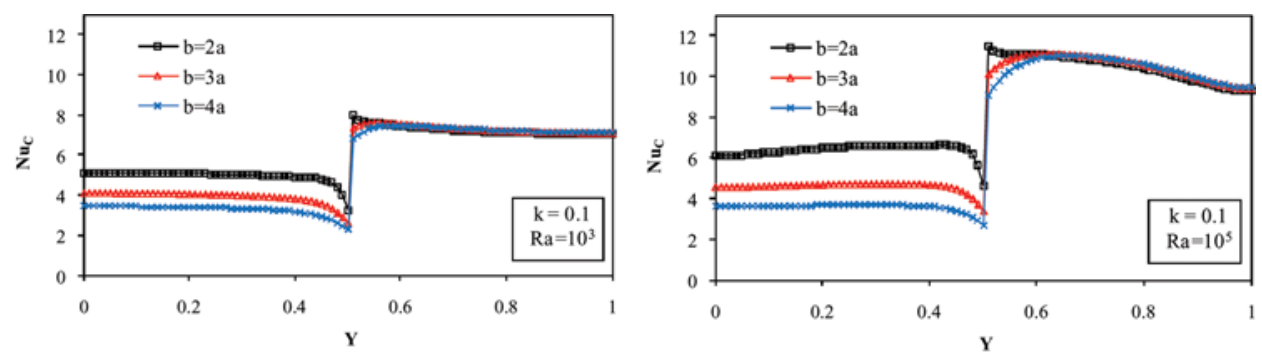

(a)
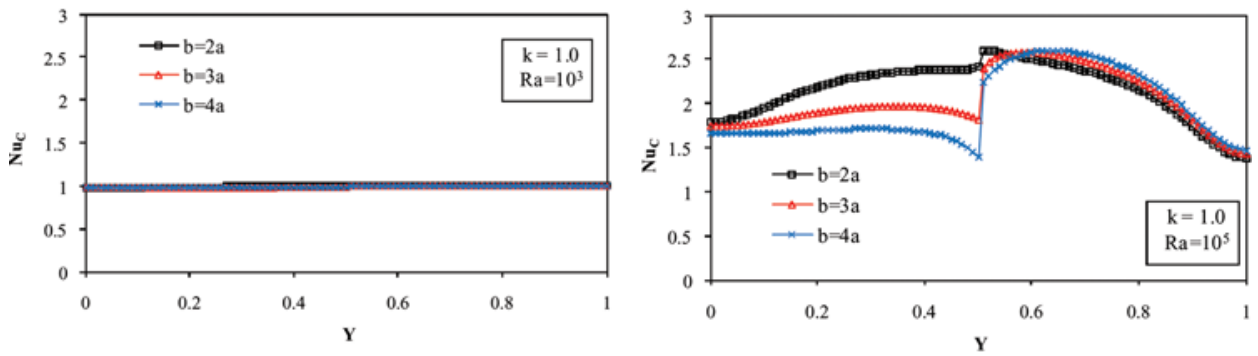

(b)
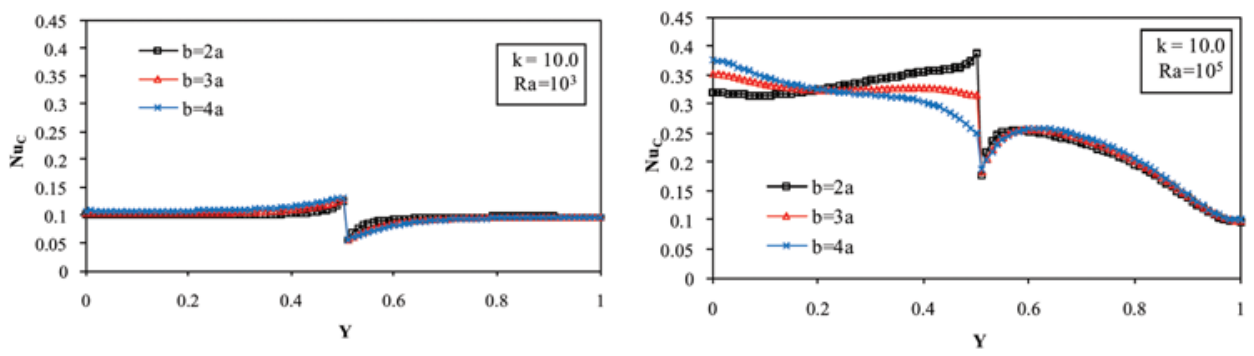

(c)

Figure 8. Variation of the cold side local Nusselt number for $\mathrm{Ra}=10^{3}$ (on the left) and $\mathrm{Ra}=10^{5}$ (on the right) along the cold wall for different thicknesses of the partition $a$ ) $k=0.1, b) k=1.0$, and $c$ ) $k=10.0$ (color figure available online).

thermal conductivity ratio. Similarly to the velocity distribution, a maximum local Nusselt number was observed for the hot side in $\mathrm{Ra}=10^{5}, k=10$, and $b=4 a$ (Figure 7c). Figure 8 illustrates the variation of local Nusselt number for the cold side of the partition. For the cold side, the variation of the local Nusselt number, a higher value was seen in $k=0.1$ due to higher heat transfer in the cold side and lower conductivity ratio.

Figure 9 shows variation of the mean Nusselt number at the hot side of the partition as a function of the Rayleigh number at different parameters of conductivity ratio and thickness of partition for the hot and cold sides, respectively. The mean Nusselt numbers for both the hot and cold sides increase with increasing Rayleigh numbers due to increasing kinetic energy with incoming energy into the system. Higher heat transfer values are obtained at higher conductivity ratio $k=10$ 


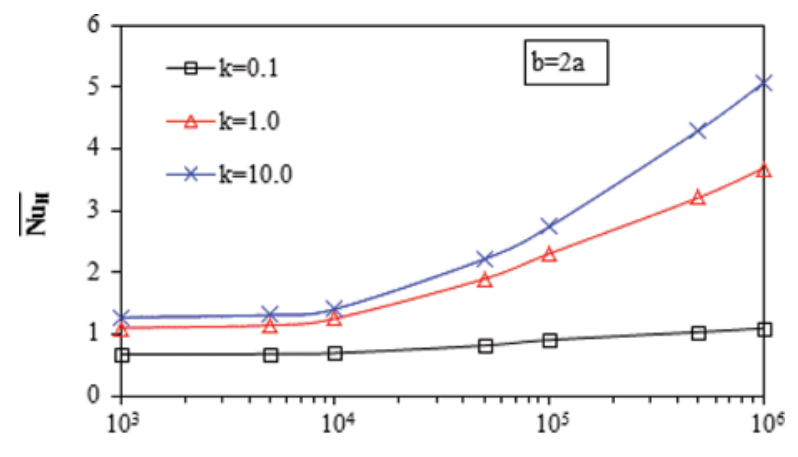

$\mathbf{R a}$

(a)

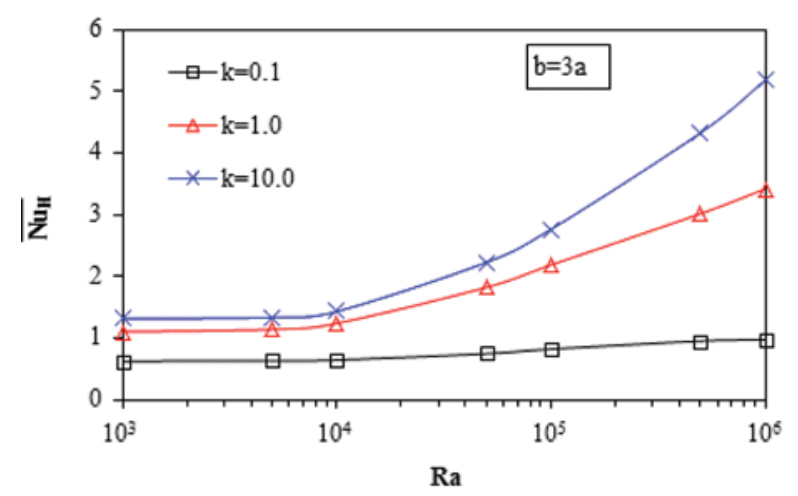

(b)

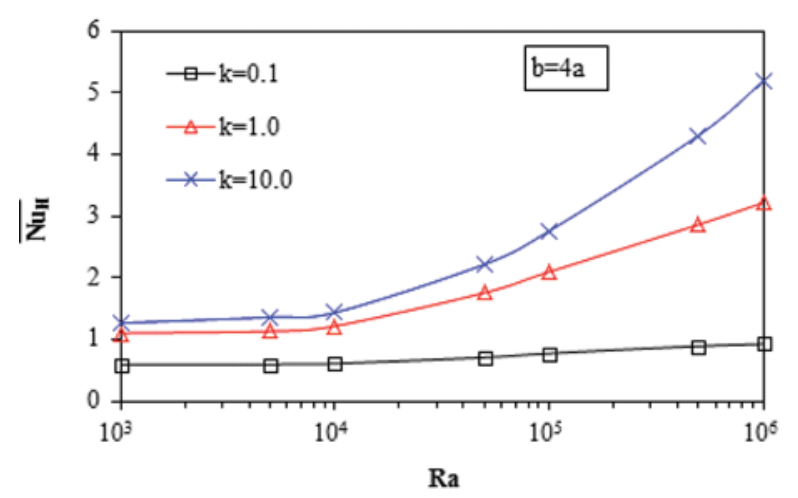

(c)

Figure 9. Variation of mean Nusselt number with Rayleigh number at different conductivity ratio $(k)$ for the hot side $a$ ) $b=2 a, b) b=3 a$, and $c$ ) $b=4 a$ (color figure available online).

(Figures $9 a-9 c$ ). It is shown in the figure, the heat transfer regime is conduction for $k=0.1$, since the mean Nusselt number is not changed with Rayleigh number. The change of partition thickness at the lower region does not have an important effect 
on the average Nusselt number of the partition. Figure 10 shows the change of mean Nusselt number of the partition cold side with Rayleigh number for different values of thermal conductivity ratio and partition thickness. For $k=0.1$, a uniform distribution is observed for the mean Nusselt number at the cold side since no motion of fluid

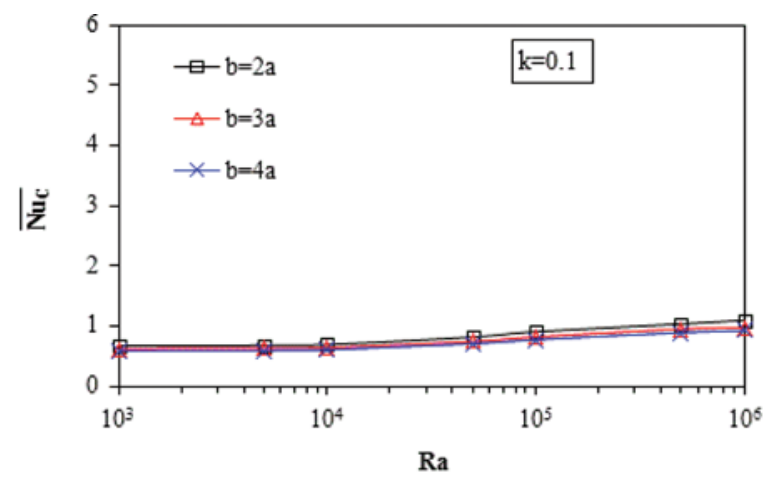

(a)

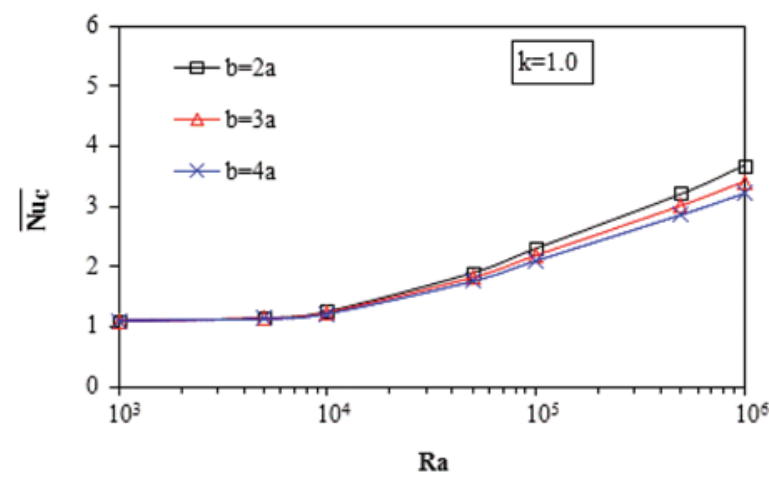

(b)

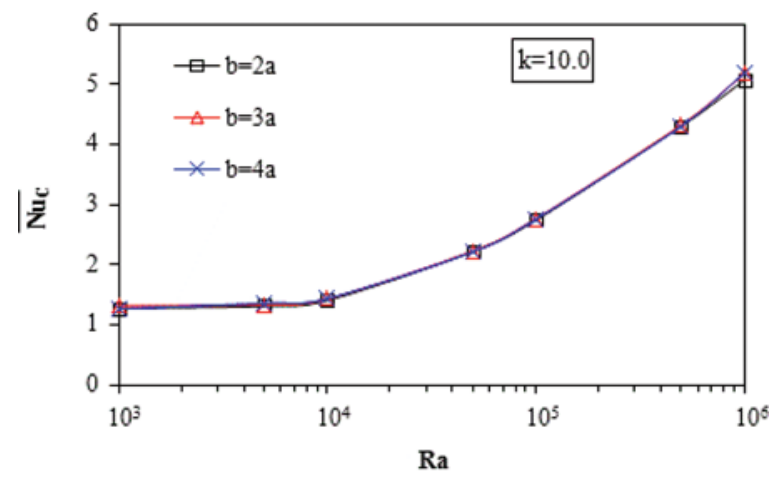

(c)

Figure 10. Variation of mean Nusselt number with Rayleigh number at different conductivity ratio $(k)$ for the cold side. a) $k=0.1, b) k=1$, and c) $k=10$ (color figure available online). 
exists in the right region. By increasing thermal conductivity ratio from 0.1 to 1 , air motion in the right cavity increases and thus the transfer of heat from the partition to the cold wall is improved. That is why the mean Nusselt number of the cold side of the partition increases particularly for high values of Rayleigh number. Further increase in thermal conductivity ratio from 1 to 10 also enhances the heat transfer rate (Figure 10c). The interesting point is that the change of the partition thickness at the lower region of the cavity does not have any effect on the heat transfer rate through the cavity. As shown in the figure, the study is important for higher Rayleigh numbers and for lower thermal conductivity ratio. It shows us that there is an optimal result for both flow and geometrical parameters. Future work can be extended for further parameters, such as partition location and different working fluids.

\section{CONCLUSION}

A numerical study has been performed to analyze the natural convection heat transfer, fluid flow, and heatline visualization in a gradually divided square enclosure. Important findings from the studied work are listed as follows:

- Thickness ratio is important for higher Rayleigh numbers.

- Thermal conductivity ratio plays an important role on heat transfer and distribution of temperature, velocity, and heatline. Mean Nusselt number increases with Rayleigh number and thermal conductivity ratio. It increases $100 \%$ with thermal conductivity ratio.

- For lower thermal conductivity, heat transfer becomes almost the same, but higher heat transfer is obtained with increasing thickness ratio.

- The partition behaves as backward or forward facing step flow in a vertical wall according to flow rotating motion. The change of thickness ratio from 2 to 4 does not influence streamlines, isotherms, and heatline patterns in the cavity.

- For low values of Rayleigh number, heat flows horizontally due to domination of conduction heat transfer. By increasing the Rayleigh number, heatline patterns are distorted and convection influences heatline patterns both in the right and left parts of the cavity.

- Heatline patterns and isotherms are perpendicular to each other in the partition since no convection exists.

- The heatline method shows the path of heat flow in the partition and understanding of the mechanism of heat transfer in the cavity becomes easier. The continuation of the heat transfer path from the left to right parts can be seen by using heatline patterns.

\section{REFERENCES}

1. D. A. Kaminski and C. Prakash, Conjugate Natural Convection in a Square Enclosure: Effect of Conduction in One of the Vertical Walls, Int. J. of Heat and Mass Transfer, vol. 29, pp. 1979-1988, 1986.

2. R. B. Yedder and E. Bilgen, Turbulent Natural Convection and Conduction in Enclosures Bounded by a Massive Wall, Int. J. of Heat and Mass Transfer, vol. 38, pp. 879-891, 1995. 
3. Y. Varol, H. F. Oztop, and A. Koca, Entropy Generation due to Conjugate Natural Convection in Enclosures Bounded by Vertical Solid Walls with Different Thicknesses, Int. Comm. in Heat and Mass Transfer, vol. 35, pp. 648-656, 2008.

4. Y. Varol, H. F. Oztop, and A. Koca, Effects of Inclination Angle on Natural Convection in Composite Walled Enclosures, Heat Transfer Eng., vol. 32, pp. 57-68, 2011.

5. F. Sanchez, F. Solorio, and R. Avila, Conjugate Natural Convection in a Square Cavity Heated From Below, Proc. of IMECE04, ASME International Mechanical Engineering Congress and Exposition, Anaheim, CA, pp. 1-10, 2004.

6. O. Polat and E. Bilgen, Conjugate Heat Transfer in Inclined Open Shallow Cavities, Int. J. of Heat and Mass Transfer, vol. 46, pp. 1563-1573, 2003.

7. N. H. Saeid, Conjugate Natural Convection in a Porous Enclosure: Effect of Conduction in One of the Vertical Walls, Int. J. of Therm. Sci., vol. 46, pp. 531-539, 2000.

8. N. H. Saeid, Conjugate Natural Convection in a Vertical Porous Layer Sandwiched by Finite Thickness Walls, Int. Comm. in Heat and Mass Transfer, vol. 34, pp. 210-216, 2007.

9. W. Chen and W. Liu, Numerical Analysis of Heat Transfer in a Composite Wall SolarCollector System with a Porous Absorber, Applied Energy, vol. 78, pp. 137-149, 2004.

10. H. Turkoglu and N. Yucel, Natural Convection Heat Transfer in Enclosures with Conducting Multiple Partitions and Side Walls, Heat Mass Transfer, vol. 32, pp. 1-8, 1996.

11. K. Kahveci, Natural Convection in a Partitioned Vertical Enclosure Heated with a Uniform Heat Flux, J. Heat Transfer, vol. 129, pp. 717-726, 2007.

12. K. Kahveci, A Differential Quadrature Solution of Natural Convection in an Enclosure with a Finite-Thickness Partition, Numer. Heat Transfer, Part A, vol. 51, pp. 979-1002, 2007.

13. K. Kahveci and S. Oztuna, MHD Natural Convection Flow and Heat Transfer in a Laterally Heated Partitioned Enclosure, European J. Mech. B/Fluids, vol. 28, pp. 744 $752,2009$.

14. C. J. Ho and Y. L. Yih, Conjugate Natural Heat Transfer in a Air-Filled Rectangular Cavity, Int. Comm. Heat Mass Transfer, vol. 14, pp. 91-100, 1987.

15. T. W. Tong and F. M. Gerner, Natural Convection in Partitioned Air-Filled Rectangular Enclosures, Int. Comm. Heat Mass Transfer, vol. 10, no. 3, pp. 99-108, 1986.

16. A. Kangni, B. Yedder, and E. Bilgen, Natural Convection and Conduction in Enclosures with Multiple Vertical Partition, Int. J. Heat Mass Transfer, vol. 34, pp. 2819-2825, 1991.

17. S. Kimura and A. Bejan, The Heatline Visualization of Convective Heat Transfer, J. Heat Transfer-Trans. ASME, vol. 105, pp. 916-919, 1983.

18. R. S. Kaluri, R. Anandalakshmi, and T. Basak, Bejan's Heatline Analysis of Natural Convection in Right-Angled Triangular Enclosures: Effects of Aspect-Ratio and Thermal Boundary Conditions, Int. J. of Therm. Sci., vol. 49, pp. 1576-1592, 2010.

19. A. Dalal and M. Kumar Das, Heatline Method for the Visualization of Natural Convection in a Complicated Cavity, Int. J. of Heat and Mass Transfer, vol. 51, pp. 263-272, 2008.

20. R. S. Kaluri, T. Basak, and S. Roy, Heatline Approach for Visualization of Heat Flow and Efficient Thermal Mixing with Discrete Heat Sources, Int. J. of Heat and Mass Transfer, vol. 53, pp. 3241-3261, 2010.

21. T. Basak, S. Roy, and I. Pop, Heat Flow Analysis for Natural Convection within Trapezoidal Enclosures based on Heatline Concept, Int. J. of Heat and Mass Transfer, vol. 52, pp. 2471-2483, 2009.

22. T. Basak, D. Ramakrishna, S. Roy, A. Matta, and I. Pop, A Comprehensive Heatline based Approach for Natural Convection Flows in Trapezoidal Enclosures: Effect of Various Walls Heating, Int. J. of Therm. Sci., vol. 50, pp. 1385-1404, 2011.

23. M. Mobedi and H. F. Oztop, Visualization of Heat Transport using Dimensionless Heatfunction for Natural Convection and Conduction in an Enclosure with Thick Solid Ceiling, Computers \& Mathematics with Applications, vol. 56, pp. 2596-2608, 2008. 
24. Q. Deng and G. Tang, Numerical Visualization of Mass and Heat Transport for Conjugate Natural Convection/Heat Conduction by Streamline and Heatline, Int. J. of Heat and Mass Transfer, vol. 45, pp. 2373-2385, 2002.

25. Y. Varol, H. F. Oztop, M. Mobedi, and I. Pop, Visualization of Natural Convection Heat Transport using Heatline Method in Porous Non-Isothermally Heated Triangular Cavity, Int. J. of Heat and Mass Transfer, vol. 51, pp. 5040-5051, 2008.

26. Y. Varol, H. F. Oztop, M. Mobedi, and I. Pop, Visualization of Heat Flow using Bejan's Heatline due to Natural Convection of Water Near $4^{\circ} \mathrm{C}$ in Thick Walled Porous Cavity, Int. J. of Heat and Mass Transfer, vol. 53, pp. 1691-1698, 2010. 